\title{
Effect of micro-pores on cracks formation in metallurgical coke
}

\author{
Stanislav Gornostayev, ${ }^{*}$ Jyrki Heino and Timo Fabritius
}

Process Metallurgy Research Unit, University of Oulu, BOX 4300, Oulu, 90014, Finland

\begin{abstract}
The relationships of micro-pores and cracks in metallurgical coke have been investigated by optical microscope and FESEM, using surface section samples. The pores have circular, elliptical and irregular shapes with smooth outlines, formed during the thermoplastic stage of the coking process. They often associate with connecting cracks between neighbouring pores. In case of elliptical pores, the connecting cracks are usually oriented along the longer axis of the pore. The connecting cracks can be developed between the pores, depending on their size and the distance between them. The coke with a large number of small pores rather than with a small number of larger pores will have lower strength due to the increased amount of connecting cracks. When compared to circular pores, elliptical and flattened pores have a lower ability to resist load pressure. Nano-sized pores have polygonal outlines, indicating an "explosion"-type formation in the solidified matrix.
\end{abstract}

Keywords: Pyrometallurgy, Metallurgical Coke, Pores, Cracks

Corresponding author

*S. Gornostayev. E-mail: Stanislav.Gornostayev@oulu.fi

(1)

\section{Introduction}

The porosity (size, shape and distribution) and the presence of cracks in metallurgical coke are among the major factors controlling its strength. ${ }^{1-4}$ The formation of pores is controlled by the gas phase and thermoplastic properties of carbon-based matrix of coking coals, when the highest fluidity provides the most porous semi-coke, presenting a large average pore size and clear signs of pore coalescence. ${ }^{5}$ Also, the properties of mesophase can affect the average pore size, the wall thickness, the number of pores present in a given area, and the degree to which the pores coalesce. ${ }^{6}$ The formation of cracks in metallurgical coke begins during the last stage of the coking process, when the carbon-based matrix of coke is already solidified. The appearance of cracks is related to the coking pressure as well as the cooling 
of coke after it was pushed out of the coke oven. The cracks also develop as a result of mechanical stress - during the coke being pushed out of the oven, transportation, charging to the blast furnace (BF) and load pressure during the $\mathrm{BF}$ process. Most of the investigations on the porosity of coke have been done in a macro-level or with the application of optical microscopy. There are also some simulation models and quantitative estimations on pores in relation to the formation of cracks and to the strength of coke in general..$^{1-4}$

Our earlier studies indicate that there is also porosity associated with the decomposition of inclusions of coal-associated minerals. ${ }^{7}$ Based on that, we divided the porosity, depending on the nature and properties of the material, into carbon- (matrix-) related and mineral-related. We also reported that there also mineral-associated cracks, which appear along grain boundaries of quartz ${ }^{8}$ and $\operatorname{spinel}^{9}$ during coking and $\mathrm{BF}$ processes.

The objectives of this study were to investigate micro- and nano-scale details of carbon- (matrix-) related porosity, in order to see how the size, shape and distribution of the smallest pores can be linked to the appearance and development of cracks, and to describe the initial mechanisms of cracks formation in a micro-level. In addition to that, comparison of the results with theoretical data and calculations on this subject has been planned to see how well the theoretical data correlate with observations on samples of industrial coke.

(2)

\section{Experimental}

For detailed investigations of metallurgical coke by optical microscope (including an automated texture analysis, ${ }^{10}$ Raman microscope,${ }^{11}$ scanning electron microscope (SEM/FESEM), ${ }^{9}$ and electron microprobe (EPMA), ${ }^{12}$ we use three types of coke samples, ${ }^{13}$ including (Fig. 1) mounted polished sections, unmounted polished sections, and surface section samples. For this study, all types of the samples have been prepared from industrial (feed) coke.

\section{PLACE FOR FIGURE}

Figure 1. General view of mounted (1) and unmounted (2) polished sections, and surface section (3). 
Mounted polished sections were prepared with low-viscosity epoxy resin and a single side of the section was carefully polished according to a procedure reported earlier. ${ }^{13}$ Unmounted polished section pieces were cut from both sides and their typical size was $25 \times 25 \times 10 \mathrm{~mm}$. The grinding and polishing of one side were done using SiC abrasive papers. Either air or ethanol was used as coolant. Surface section samples are intact, unpolished dry-cut samples prepared for investigations of features that can be found on authentic surface of coke, including original textures and morphologies, ${ }^{14}$ appearance of mineral matter, ${ }^{15}$ relationships between the coke matrix and associated mineral matter, ${ }^{9}$ interaction of coke with droplets of molten iron ${ }^{16}$ and the formation of graphite. ${ }^{17}$ The samples were preliminary studied with optical microscope. After that they were investigated mostly with a high resolution Field Emission Scanning Electron Microscope (FESEM) Zeiss ULTRA plus and, in a few occasions, with Jeol GSM-6400 Scanning Electron Microscope (SEM) operated at $15 \mathrm{Kv}$.

(3)

\section{Results and discussion}

It was observed that polished sections (Fig. 2A) are useful for the evaluation of pore shapes in a crosssection, their size and relationship to each other, but it was difficult to see any cracks there. Unmounted polished sections (Fig. 2B) provide more information by observation of cracks inside the pores. Nevertheless, the cracks could not be traced outside the pores on polished surface of the samples. It seems that the cracks in both types of the samples have been hidden (healed) during grinding and polishing due to the softness of the carbon-based matrix. The most useful for the investigations of pores and cracks and their relationships were surface section samples (Fig. 2C). Therefore, the majority of data presented below have been obtained from this type of sample using FESEM.

Our investigations with optical microscope and FESEM have revealed the variations of porosity size, which can be documented under different magnifications. Fig. 1 (optical microscope, pore size $1 \mathrm{~mm}$ and above) and Fig. 2C (FESEM, low magnification) demonstrate macro-porosity, which can be also noticed in the samples by the naked eye. In Figures 2A, 2B, 3 and 6A, the pores of micro-size (from $4 \mu \mathrm{m}$ to $1 \mathrm{~mm}$ ) can be seen, while Fig. 6B describes nano-sized (less than $1 \mu \mathrm{m}$ ) porosity. Therefore, the pores can be generally divided into macro- (seen by the naked eye, optical microscope or with low 
magnification under FESEM - $1 \mathrm{~mm}$ and above), micro- $(1 \mu \mathrm{m}-1 \mathrm{~mm})$ and nano-size pores $(<1 \mu \mathrm{m})$. The last two types of porosity have been investigated in details.

Micro-pores have circular, elliptical and irregular (formed by coalescence of smaller neighbouring pores) shapes in a cross-section. They all have smooth outlines (Fig. 2A; Fig. 3), formed during the thermoplastic stage of the coking process. The formation of elliptical (elongated) shapes of the pores (Figs. 3C and 3D) can be related to coking pressure and plasticity of the coke mass. Generally speaking, the higher the plasticity and the pressure, the more distinct elliptical and flattened shapes can be formed.

\section{PLACE FOR FIGURE}

Figure 2. Cracks and pores in metallurgical coke, FESEM. Mounted (A) and unmounted (B) polished sections, and surface section (C).

\section{PLACE FOR FIGURE}

Figure 3. Micro-pores and cracks in metallurgical coke. Surface section samples, FESEM.

First cracks probably appear in coke during the last stage of coking process and then during cooling, after it was pushed out of coke oven. In this case, they have a radial shape around pores (Fig. 3F) indicating textural differences of the material in the direction from the pore wall further to the matrix. The other (and more important) reason for crack formation is mechanical stress, when coke is moved (transported) and loaded to BF. The formation of these stress-related cracks depends on the pressure as well as properties of the coke matrix itself. As it was revealed during this study, the porosity of coke has a substantial influence on micro cracks formation (initial cracks).

The micro-pores often associate with cracks, which connect two or more neighbouring pores (Figures $3 \mathrm{C}$ and $3 \mathrm{E}$ ). In the case of elliptical pore shapes, the connecting cracks often go along the longest axis of the pores (Figures 3C and 3D); while comparable in size (and even larger) rounded pores more often have no cracks around them (Figures 3A and 3B). This observation is in agreement with the results on assessment of coke strength by numerical analysis by Asakuma et al., ${ }^{1}$ who stated that the stress can be easier concentrated at the pore wall for flatter pore than circular pore. The data on quantitative evaluation of relationships between pore structure and coke strength by Kubota et al., ${ }^{3}$ who concluded that the amount of low roundness pores and coke strength are in a good correlation, also support our observation. 
Comparable results have been also obtained by Saito et al., ${ }^{4}$ who reported that in the model with randomly shaped pores, the presence of large irregularly shaped pores caused the decrease of coke strength. Perhaps, our data can be used for validation of some existing models on the relationships of porosity and strength.

The phenomenon of relationships of shape and strength can be also explained more generally (not only for metallurgical coke) by the anisotropy of properties of elliptic shapes compared to circular ones. ${ }^{18}$ So, the direction along the longest axis of elliptical pores may exhibit the lowest ability for resisting pressure compared to circular pores (that have the same size in a cross section). This conclusion is also valid for all elongated and flattened pores where the length of a pore is higher than the width (Fig. 4). Taking into account the results and discussion above, one can also make a reference on coking pressure, since it has an effect on the pore shape. The higher the coking pressure, the more flattened pores will be formed, thus detracting from the coke strength.

\section{PLACE FOR FIGURE}

Figure 4. Cracks formed on long axis of flattened (elongated) micro-pore. Surface section sample, SEM, scale bar $-200 \mu \mathrm{m}$.

The development of connecting cracks between the pores probably depends on their size (diameter of circular pores or length of the larger axis in elliptical pores) and the distance between them. One noticeable observation is that in some cases the areas with circular pores of 40-100 $\mu \mathrm{m}$ in diameter have very few or no cracks at all (Figures $3 \mathrm{~A}$ and $3 \mathrm{~B}$ ). This is especially the case when the pores are small and the distance between them is sufficiently far. Preliminary data collected from the studied samples show that it often the case when the distance is more than $100 \mu \mathrm{m}$ and the diameter of the pores is less than 20 $\mu \mathrm{m}$, giving the ratio 5:1. Any increase of the diameter of the pores and/or decrease of the distance between them raises the probability of crack formation. This can be seen in Fig. 3E, where closely located (20-100 $\mu \mathrm{m})$ small $(10-40 \mu \mathrm{m})$ pores have connecting cracks between each other. It seems that even if small rounded pores (not only large and elliptical) are located close to each other, then the development of cracks is possible between them. This fact probably means that when the tensions near neighbouring pores are high enough and the distance is sufficient, then the interconnection cracks can be formed. The last statement correlates with observed but not sufficiently discussed phenomena that the compressive 
strength was highest for cokes with a large number of small pores rather than a small number of large

pores. ${ }^{6}$ It seems obvious that the situation when the pores occur close to each other is typical for cokes with randomly distributed porosity, when some part of the matrix is free of the pores (Fig. 3B), while the other hosts more closely located pores, thus detracting from the coke strength. This suggestion is in agreement with the results on simulation of effect of pore structure on coke strength by Kim et al., ${ }^{2}$ who reported that if large pores have regular distribution then they strengthen the coke in comparison with the cases when pores are arranged randomly. The general model for the formation of connecting cracks between micro-pores is presented on Fig. 5.

We reported recently [10] that the addition of high density polyethylene (HDPE) to coking coals can cause the appearance of rounded $(50 \mu \mathrm{m})$ and elliptic $(50 \times 200 \mu \mathrm{m})$ pores surrounded by anisotropic (highly reactive) carbon in experimental coke. It means that the porosity can be partly controlled by the addition of HDPE and, consequently, it will have an effect on the strength of the coke.

Unlike micro-pores, nano-sized pores (Fig. 6) usually exhibit polygonal boundaries, indicating "explosion"-type formation (breakage) in the solidified matrix at the end of the coking process. The tiniest cracks are formed around nano-sized pores (Fig. 6B). They can probably grow to create larger cracks when the coke is exposed to mechanical stress (load pressure in a BF). Nano-pores often occur as a group or chains of several pores located 0.1-2 $\mu \mathrm{m}$ from each other (Fig. 6B).

\section{PLACE FOR FIGURE}

Figure 5. General model for the formation of connecting cracks between micro-pores (in a cross section).

\section{PLACE FOR FIGURE}

Figure 6. Micro pores (A) and nano pores with sharp outlines and associated cracks (arrows) (B) in surface section sample, FESEM.

Since the formation of nano-sized pores takes place during the last stages of the coking process, it is then possible to suggest that the coke which produces the lowest amount of gas after its solidification will have fewer cracks related to nano-sized porosity. Such coke will likely possess higher compressive strength.

(4)

Conclusions

Based on the observations and discussion above, the following conclusions can be made: 
- Investigations of cracks and their relationships to the pores will gain the best results when using surface section samples;

- Based on size, the pores can be divided into macro- (can be studied with optical microscope), micro- and nano-size pores (FESEM and SEM observations);

- Elliptical, elongated and flattened pores compared to circular pores have lower ability to resist load pressure. They are more likely to cause the appearance of cracks thus resulting weakness in the coke. From this point of view, rounded pores indicate stronger coke;

- The connecting cracks can be formed between the pores depending on their size and the distance between them. Even if small rounded pores (not only large and elliptical) are located close to each other, then the formation of stress-related cracks is more likely between them;

- The coke with a large number of small (micro-) pores rather than with a small number of larger pores will have lower strength due to increased amount of connecting cracks;

- The cokes which produce the lowest amount of gas after its solidification will have fewer cracks related to nano-sized porosity. Such cokes probably will have higher compressive strength;

- The data obtained with high resolution scanning electron microscopy can be used for validation of some existing models on the relationships of porosity and cracks.

\section{Acknowledgements}

This research was funded by the Academy of Finland and by FIMECC within a framework of the System Integrated Metal Processes (SIMP) project. Mr. Tommi Kokkonen (Process Metallurgy Group, University of Oulu) is thanked for preparing the samples. Anonymous reviewers have provided valuable comments which improved clarity and quality of the manuscript.

\section{(6) References}

1. Y. Asakuma, M. Soejima, T. Yamamoto, H. Aoki and T. Miura: 'A new estimation method of coke strength by numerical multiscale analysis', ISIJ Int., 2003, 43, (8), 1151-1158.

2. S. Y. Kim and Y. Sasaki: 'Simulation of effect of pore structure on coke strength using 3dimensional discrete element method', ISIJ Int., 2010, 50, (6), 813-821.

3. Y. Kubota, S. Nomura, T. Arima and K. Kato: 'Quantitative evaluation of relationship between coke strength and pore structure', ISIJ Int., 2011, 51, (11), 1800-1808.

4. Y. Saito, S. Matsuo, T. Kanai, A. Toishi, A. Uchida, Y. Yamazaki, Y. Matsushita, H. Aoki, S. Nomura, H. Hayashizaki and S. Miyashita: 'Effect of random pore shape, arrangement and nonadhesion grain boundaries on coke strength', ISIJ Int., 2014, 54, (11), 2519-2526.

5. J. J. Duffy, M. R. Mahoney and K. M. Steel: 'Influence of coal thermoplastic properties on coking pressure generation: Part 2 - A study of binary coal blends and specific additives', Fuel, 2010, 89 (7), 1600-1615. 
6. N. Andriopoulos, C. E. Loo, R. Dukino, S. J. Mcguire: 'Micro-properties of Australian coking coals', ISIJ Int., 2003, 43, (10), 1528-1537.

7. S. S. Gornostayev, E-P. Heikkinen, J. J. Heino, T. M. J. Fabritius and J. J. Härkki: 'Mineral related $\mathrm{CO}_{2}$ and $\mathrm{H}_{2} \mathrm{O}$ emissions during the production of metallurgical coke', Steel Res. Int., 2013, 84 (11), 1104-1109.

8. S. S. Gornostayev, O. Kerkkonen, J. J. Härkki: 'Importance of mineralogical data for influencing properties of coke: A reference on $\mathrm{SiO}_{2}$ polymorphs', Steel Res. Int., 2006, 77, (11), 770-773.

9. S. Gornostayev, J. Härkki: "Mineral matter crystallization and crack formation in tuyere coke", Fuel, 2006, 85, (7-8), 1047-1051.

10. S. Gornostayev, J. Heino, T. Kokkonen, H. Makkonen, S. Huttunen, T. Fabritius: 'Textural changes in metallurgical coke prepared with polyethylene', Int. J. Miner. Metall. Mater., 2014, 21, (10), 969-973.

11. S. Huttunen, S. Gornostayev, T. Kokkonen and R. Mattila: 'Study of mineral phases in coke samples by Confocal Raman Microscopy'. Report 342, Department of Process and Environmental Engineering, University of Oulu, ISBN 978-951-42-9510-2, (2011), 1-59.

12. S. S. Gornostayev, E-P. Heikkinen, J. J. Heino, S. M. M. Hutunen, T. M. J. Fabritius: 'Behavior of alkali-bearing minerals in coking and blast furnace processes', Steel Res. Int., 2016, 87, (9), $1144-1153$.

13. T. Kokkonen and S. Gornostayev: 'Preparation of samples of metallurgical coke for optical and electron microscopy and electron probe microanalysis'. Report 339, Department of Process and Environmental Engineering, University of Oulu, ISBN 978-951-42-6119-0, 2010, 1-22.

14. S. S. Gornostayev and J. J. Härkki: 'Carbon tubular morphologies in blast furnace coke', Res. Let. in Materials Sci., 2008, 751630. http://doi.org/10.1155/2008/751630

15. S. Gornostayev and J. Härkki: 'Spinel crystals in tuyere coke', Metall. Mater. Trans. B., 2005, 36B, (2), 303-305.

16. S. S. Gornostayev, E-P. Heikkinen, J. J. Heino and T. M. J. Fabritius: 'Fe-Si particles on the surface of blast furnace coke', Int. J. Miner. Metall. Mater., 2015, 22, (7), 697-703.

17. S. Gornostayev and J. Härkki: 'Graphite crystals in blast furnace coke', Carbon, 2007, 45, (6), 1145-1151.

18. R. Kienzler: 'Energy changes in elastic plates due to holes and cracks', Proceedings of the Estonian Academy of Sciences 57 (2008), 26-33. http://doi.org/10.3176/proc.2008.1.03 


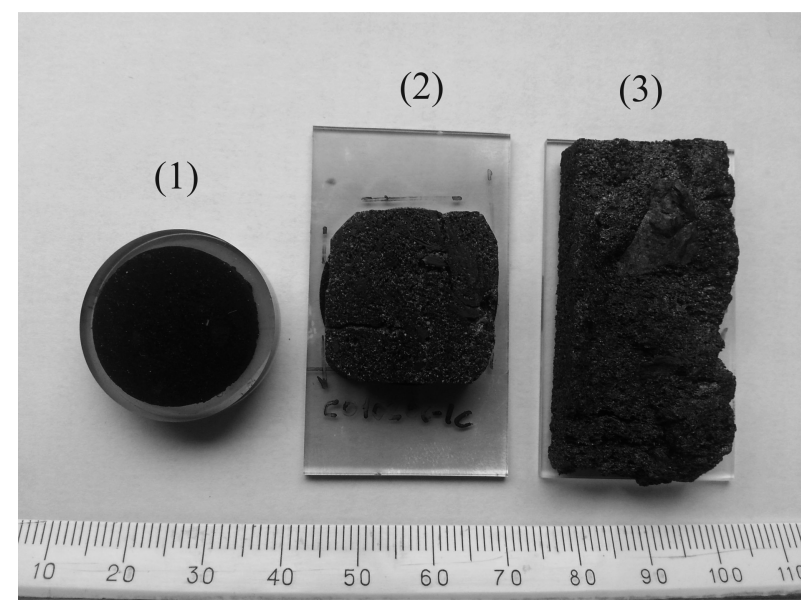

Figure. 1. General view of mounted (1) and unmounted (2) polished sections, and surface section (3).

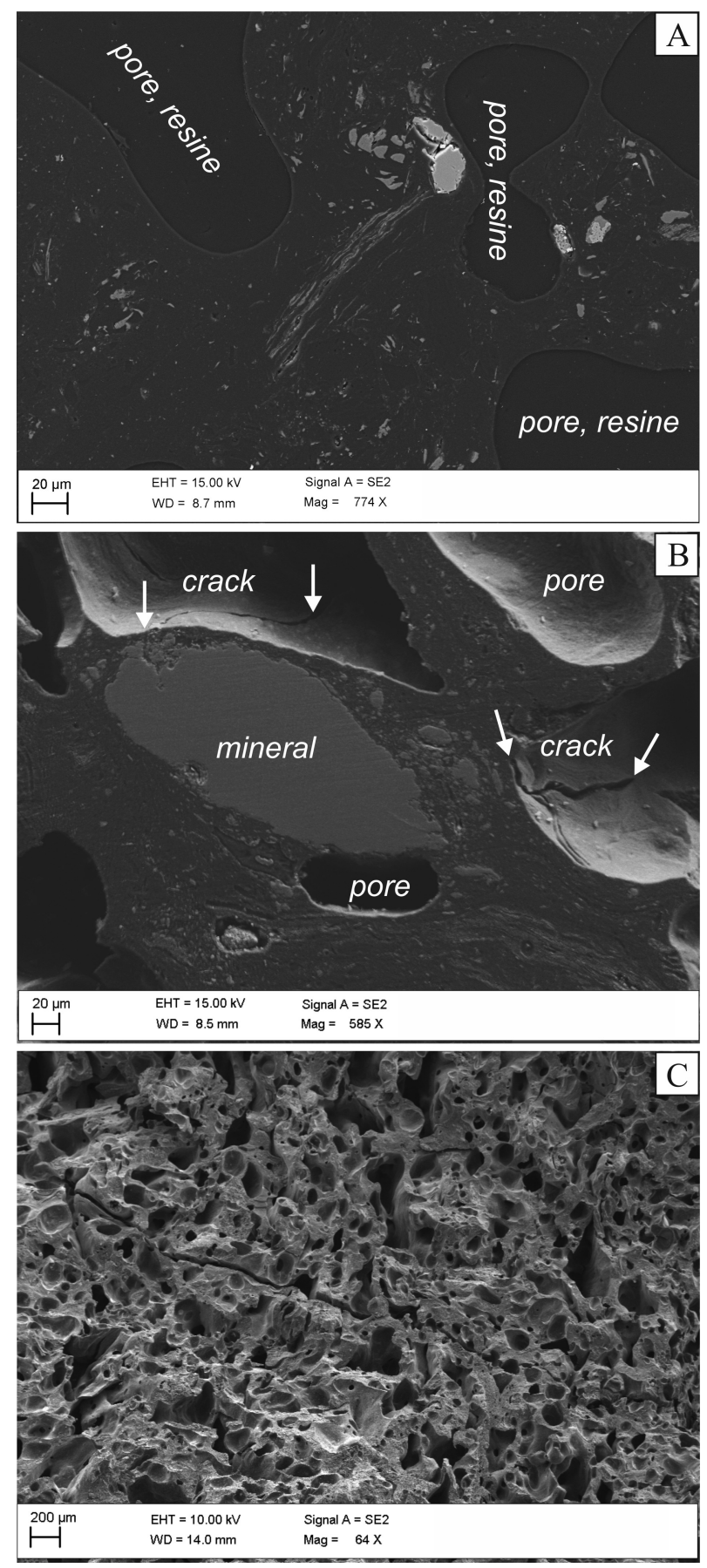

Figure 2. Cracks and pores in metallurgical coke, FESEM. Mounted (A) and unmounted (B) polished sections, and surface section (C). 


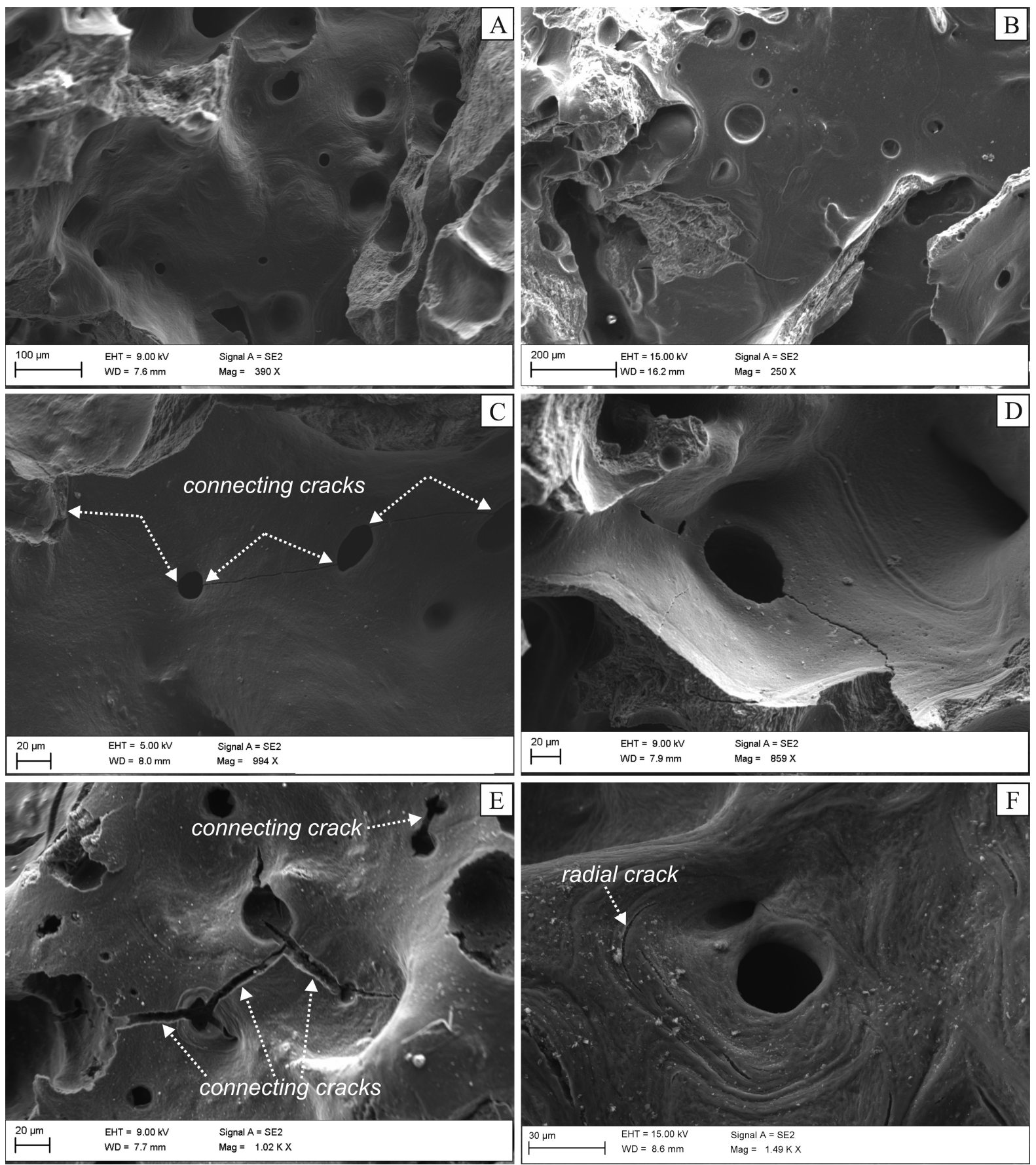

Figure 3. Micro-pores and cracks in metallurgical coke. Surface section samples, FESEM. 


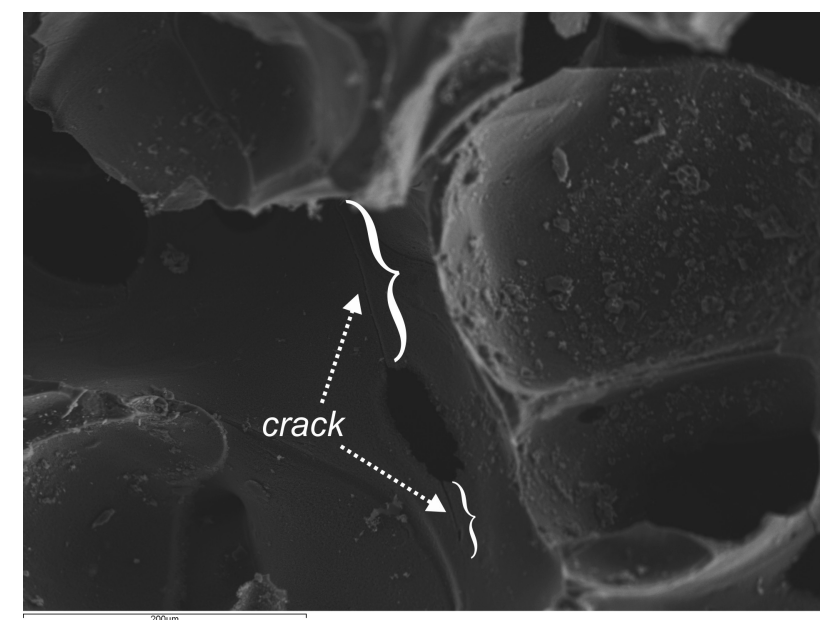

Figure 4. Cracks formed on long axis of flattened (elongated) micro-pore. Surface section sample, SEM, scale bar $-200 \mu \mathrm{m}$.

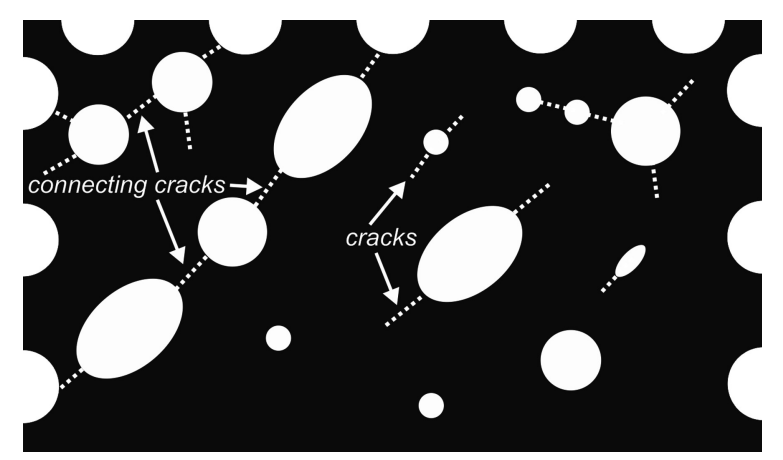

Figure 5. General model for the formation of connecting cracks between micro-pores (in a cross-section).

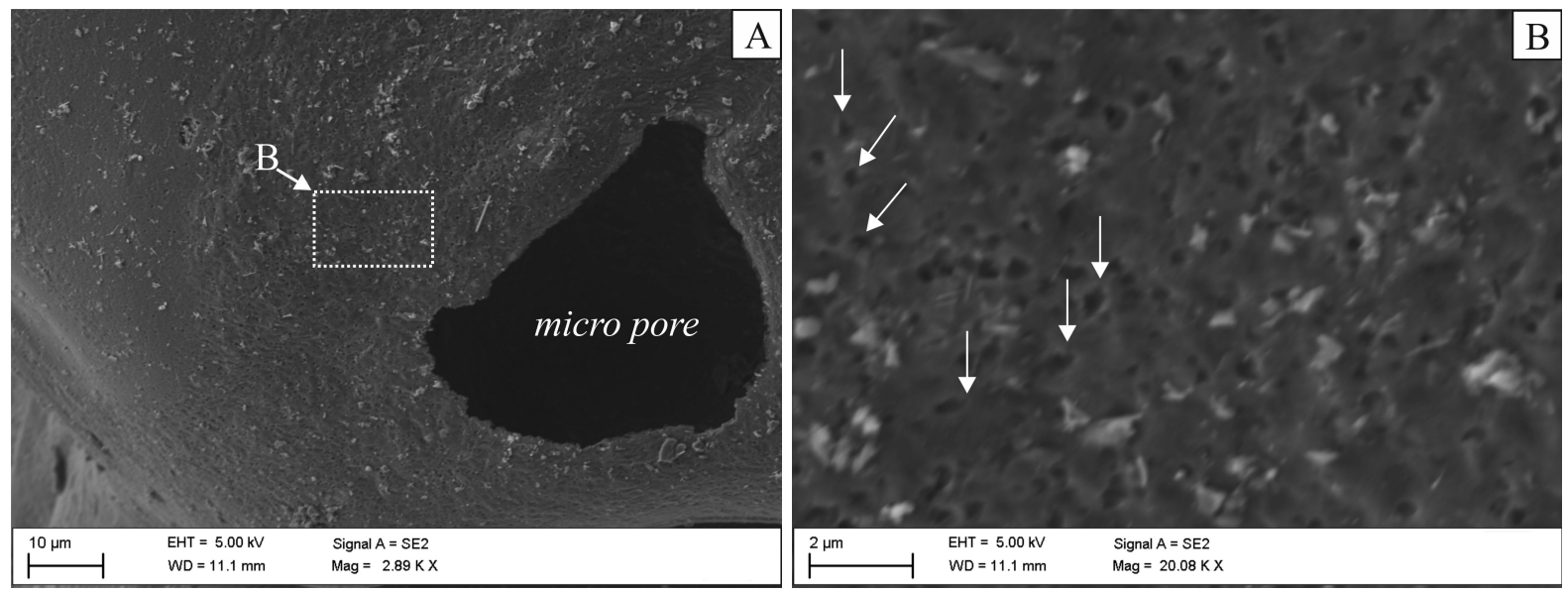

Figure 6. Micro-pores (A) and nano-pores with sharp outlines and associated cracks (arrows) (B) in surface section sample, FESEM. 